\title{
LXV. Continuation of the table of atomic weights, and notice of a new scale of equivalents
}

\author{
Mr. John Prideaux
}

To cite this article: Mr. John Prideaux (1830) LXV. Continuation of the table of atomic weights, and notice of a new scale of equivalents, Philosophical Magazine Series 2, 8:48, 423-433, DOI: $10.1080 / 14786443008675500$

To link to this article: http://dx.doi.org/10.1080/14786443008675500

里 Published online: 14 Jul 2009.

Submit your article to this journal $₫$

Џll Article views: 6

Q View related articles ๘ 
of observation and the angles $\gamma$ and $\gamma^{\prime}$ (the zenith distances of the bodies); that $\mathbf{P}$ and $\mathbf{Q}$ likewise involve $d$ and $a$, and that $u$ and $v$ contain these angles instead of $\mathrm{D}$ and $\mathrm{A}$. It is therefore not necessary to give particular methods for the calculation of eclipses, be they either eclipses of the sun or transits of the inferior planets over the disc of the sun, as all these phænomena may be treated after the method which I have developed for the occultations of stars.

From the formulæ [14] results

$$
\begin{aligned}
& \mathrm{G}^{2}=\sin \pi^{2}-2 \sin \pi \cdot \sin \pi^{\prime} \cdot \cos \sigma+\sin \pi^{\prime} \\
& \operatorname{tang}(\mathrm{A}-a)^{\cdot}=\frac{\sin x^{\prime} \cos \delta \sin (\alpha-A)}{\sin \pi \cdot \cos \mathrm{D}-\sin \pi^{\prime} \cos \delta \cos (\alpha-A)}
\end{aligned}
$$

where $\sigma$ stands for the geocentric distance of the two bodies. For a solar eclipse we may put

$$
\begin{aligned}
& \mathrm{G}=\sin \pi-\sin \pi^{\prime} \\
& a=\mathrm{A}-\frac{\sin \pi^{\prime}}{\sin \pi}(\alpha-\mathrm{A}) \\
& d=\mathrm{D}-\frac{\sin x^{\prime}}{\sin \pi}(\delta-\mathrm{D}) \text { without causing in the cal- }
\end{aligned}
$$

culation any perceptible deviation from the truth. The quantities whose introduction has so much contracted the formulx will then be found almost without calculation, and the calculation of solar eclipses will in point of ease present only insignificant differences from those of occultations of stars. We have here another confirmation of the remark which one has so often occasion to make, - that the rigorous mathematical solution of astronomical problems ceases to require more difficult calculations than the approximately correct ones, as soon as one has succeeded in representing the former in its true shape.

F. W. BesseL.

LXV. Continuation of the Table of Atomic Weights, and Notice of a new Scale of Equivalents. By Mr. JoHN PRIDEAUx, Member of the Plymouth Institution.

To the Editors of the Philosophical Magazine and Annals.

Grentlemen, Plymouth, Aug. 8th, 1830.

T BEG leave now to send you the Table of acids and bases, and a description of the scale, which has already intruded on so many of your pages. 
424 Mr. Prideaux's Continuation of the Table of Atomic Weights,

Table of Salifiuble Bases.

\begin{tabular}{|c|c|c|c|}
\hline & Thomson. & Berzelius. & Mean. \\
\hline Alumina ......... & Ai 2.25 & $\ddot{A} i_{2} 64.2 \cdot 334$ & $2 \cdot 2 A i(a)$ \\
\hline Ox. antimony .... & $\dot{A n} 6.5$ & $\ddot{A n^{2}} 1912 \cdot 904$ & $6.5 \operatorname{An}(a)$ \\
\hline Baryta ......... & $B \dot{a} 9 \cdot 75$ & 956.88 & $9 \cdot 66 *$ \\
\hline Ox. bismuth ...... & $B s 0^{\circ}$ & $\ddot{B} s^{8} 2690 \cdot 752$ & 10. $B \dot{s}(c)$ \\
\hline - cadmium.... . . & $C \dot{d} 8$ & $796 \cdot 767$ & $8 \cdot$ \\
\hline- cerium....... & $C e \cdot 7 \cdot 25$ & $674 \cdot 718$ & $7 \cdot$ \\
\hline Sesquiox. cerium. . & $\ddot{C} e^{2} 15 \cdot 5$ & $1449 \cdot 436$ & $15 \cdot$ \\
\hline Ox. chrome...... & $5 \cdot$ & $\ddot{C} r^{2} 1003 \cdot 638$ & $10.02 \dddot{C r}_{r}(b)$ \\
\hline- cobalt ....... & Co 4.25 & 468.991 & $4 \cdot 4$ \\
\hline Perox. cobalt..... & $\dddot{C} o^{*} 9 \cdot 5$ & $1037 \cdot 982$ & $9 \cdot 8$ \\
\hline Subox. copper.... & $\dot{C u}^{2} 9$ & $891 \cdot 39$ & $8 \cdot 96$ \\
\hline Ox. copper...... & $\dot{C u} 5$ & $495 \cdot 695$ & 4.98 \\
\hline Glucina ......... & $G \dot{G l} \quad 3.25$ & $\ddot{G} l^{2} \quad 962-958$ & $3.22 \dot{G l}(a)$ \\
\hline Ox. gold......... & $\dot{G} 26^{\circ}$ & $\dot{G}^{2} 2586.026$ & $26 \dot{G}$ \\
\hline Perox. gold...... & $\dddot{G} 28$. & $\dddot{G}^{3} 2786.026$ & $28 \dddot{G}$ \\
\hline Ox. iridium ...... & & & $13.42 \dot{I r}(c)$ \\
\hline Sesquiox. ditto .... & & & $27.84 \dddot{I}_{r^{2}}$ \\
\hline Binox. ditto...... & & No & $14 \cdot 42 \ddot{I r}$ \\
\hline Trinox. ditto ..... & & & $15.42 \dddot{I r}$ \\
\hline Ox. iron $\ldots \ldots \ldots$ & $\dot{F} 4.5$ & $4: 39 \cdot 213$ & $4 \cdot 4.5$ \\
\hline Sesquiox. ditto... & $\dddot{F}^{2} 10$ & $978 \cdot 426$ & $9 \cdot 9$ \\
\hline Ox. lead ..... & $\dot{L} 14$. & $1394: 498$ & 14. \\
\hline Lime....... & $C \dot{C a} 3 \cdot 5$ & 356.019 & $3 \cdot 53$ \\
\hline Lithia ... . & $\dot{L} i \quad 2 \cdot 25$ & $227 \cdot 757$ & $2 \cdot 26$ \\
\hline Magnesia... & $M \dot{g} 2 \cdot 5$ & $258 \cdot 353$ & $2 \cdot 54$ \\
\hline Ox. manganese... & $\operatorname{Mn} 4 \cdot 5$ & $455 \cdot 787$ & $4 \cdot 53$ \\
\hline Sesquiox. ditto ... & $\ddot{M n^{2}} 10$ & $1011 \cdot 575$ & $10 \cdot 06$ \\
\hline
\end{tabular}

* Where the constituent sign corresponds in all three columns, it is stated only in the first, to save needless repetition of this troublesome work to the printer. 
and Notice of a new analytical Scale of Equivalents. 425

TABLE (concluded).

\begin{tabular}{|c|c|c|c|}
\hline & Thomson. & Berzelius, & Mean. \\
\hline Binox. manganese & $\dot{M} \dot{n} 5 \cdot 5$ & 555.785 & 5.53 \\
\hline Ox, molybdenum... & Mo $7 \cdot$ & $\ldots$ & 7 \\
\hline Subox. mercury ... & $\dot{M} 26$ & $\dot{M}^{2} 2631 \cdot 645$ & $26 \cdot 1 \dot{M}(a)$ \\
\hline Ox. ditto....... & $\ddot{M} 27 \cdot$ & $\dot{M} 1365 \cdot 822$ & $13.55 \dot{M}$ \\
\hline Ox. nickel... . . . . & $\dot{N} 4.25$ & $469 \cdot 675$ & $4 \cdot 4$ \\
\hline Sesquiox. ditto .... & $\dddot{N}^{2} 9 \cdot 5$ & $\ldots$ & $9 \cdot S$ \\
\hline Ox. osmium..... & & 0 & $13.53 O S(c)$ \\
\hline Binox. ditto...... & & & $14.53 \dot{O s}$ \\
\hline Quadrox. ditto.... & & & $1653 O_{s}$ \\
\hline Ox. palladium .... & & Note $(c)<$ & $7 \cdot 7 \mathrm{Fa}$ \\
\hline Binox. ditto...... & & & $8 \cdot 7 \dot{P a}$ \\
\hline $\mathrm{Ox}$ : platinum ..... & & & $13.42 P_{t}$ \\
\hline Binox. ditto. ..... & & & $14 \cdot 4 \cdot 2 \ddot{p} t$ \\
\hline Potash .... & $\ddot{P}_{0} 6$ & $589 \cdot 916$ & 595 \\
\hline Sesq. ox. rhodium. & $\cdots$ & $(c)$ & $16 \cdot 12 \dddot{R}_{2}$ \\
\hline Ox, silver... & $A \dot{g} 14.75$ & $1451 \cdot 607$ & 1463 \\
\hline Soda........... & So $4^{\circ}$ & $390 \cdot 897$ & $3 \cdot 96$ \\
\hline Strontia........ & $S \dot{S} \quad 6.5$ & $647 \cdot 285$ & 6.5 \\
\hline Ox. tellurium .... & $\dot{T} l 5^{-}$ & $\ddot{T l} 1006 \cdot 452$ & $5 \cdot \dot{T l}$ \\
\hline Thorina ........ & $\cdots$ & $\dot{T h} \quad 844 \cdot 9$ & $8 \cdot 45$ \\
\hline Ox. tin..... & $\dot{T} \quad 9.25$ & $835 \cdot 294$ & $8 \cdot 3$ \\
\hline Binox. ditto ...... & $\ddot{T} \quad 925$ & 935.294 & $9 \cdot 3$ \\
\hline Ox, titanium..... & $\dot{T i} 5$ & $\cdots$ & 495 \\
\hline - uranium ..... & $\dot{U} \quad 27$ & $2811 \cdot 36$ & $27 \cdot 5$ \\
\hline Binox. ditto.. & $\ddot{U} 28$ & $\dddot{U}_{2} \quad 5722 \cdot 72$ & $56 \cdot \dddot{U}^{2}$ \\
\hline Yttria ... & $\dot{Y} \quad 5.25$ & $501 \cdot 840$ & $5 \cdot 14$ \\
\hline Ox. zinc... & $\dot{Z} \quad 5.25$ & $503 \cdot 226$ & $5 \cdot 2$ \\
\hline Zirconia.. & $Z r \quad 6$. & $\ddot{Z} \ddot{r}^{2} 1140 \cdot 476$ & $5 \cdot 6 \dot{Z} r(a)$ \\
\hline
\end{tabular}

N.S. Vol. 8. No. 48. Dec. 1830. 3 I $\quad$ (a.) Alumina. 
(a.) Alumina, glucina, zirconia ; oxides of antimony, bismuth and mercury: see the notes on the respective metals appended to the Table of undecomposed bodies. (See supra, p. 163 , et seq.)

(b.) Oxide of chrome.-Thomson, correcting his number for this oxide in the First Principles, makes it (Ann. Phil. second series, vol. vi.) chrome 1 atom, oxygen $1 \frac{1}{2}$ atom : a formula, of which even its high authority does not demonstrate an advantage commensurate with its verbal inaccuracy. In signification it corresponds with that of Berzelius.

(c.) Oxides of iridium, osmium, palladium, platinum and rhodium, are taken from the paper of Berzelius quoted in the note on these metals appended as above referred to; but with adjustment to the mean weight of chlorine.

(d.) Peroxide of uranium.-The constitution assigned by Berzelius to this oxide seems to me rather confirmed than invalidated by 'Thomsun's experiments.

TABre of Acids.

\begin{tabular}{|c|c|c|c|}
\hline & Thomson. & Berzelius. & Mean: \\
\hline Acetic........ & 625 & $\cdots$ & $6.27(a)$ \\
\hline Antimonic....... & $A \ddot{n} \quad 7 \cdot 5$ & $\ddot{A n}^{2} 2112.9$ & $7.5 \mathrm{An}(b)$ \\
\hline Arsenious ........ & As $\quad 6.75$ & 1440 & $6.73 \quad \ddot{A s}(c)$ \\
\hline Arsenic ......... & $\ddot{A s} \quad 7.75$ & 164008 & $7.73 \ddot{\mathrm{As}}(c)$ \\
\hline Benzoic......... & 15. & $1509 \cdot 55$ & $15 \cdot 1 \quad(d)$ \\
\hline Boracic.......... & $\ddot{\mathrm{B}} 3$. & $2 \dddot{B} \quad 871 \cdot 966$ & $2.95 \ddot{B}(e)$ \\
\hline crystallized & $\ldots$ & $\ldots$ & $5 \cdot 2 \ddot{\mathrm{B}} A q^{2}$ \\
\hline Carbonic.... & $\ddot{\text { C } \quad 2.75}$ & 276.437 & $2 \cdot 76$ \\
\hline Chloric ......... & $\ddot{C} \dot{l} \quad 9.5$ & 94265 & $9 \cdot 46$ \\
\hline Perchloric...... & $\ddot{c} i 11.5$ & $\mathrm{Cl} 1042 \cdot 65$ & $11 \cdot 46 \ddot{\mathrm{c}}(f)$ \\
\hline Chloriodic........ & $\mathrm{Cl}_{21} \mathrm{24} \cdot 5$ & $\cdots$ & $24 \cdot 72 \quad(g)$ \\
\hline Chromic..... & $\ddot{\mathrm{C}} \mathbf{r} \quad 6.5$ & $651 \cdot 819$ & 6.51 \\
\hline Citric....... & $7 \cdot 25$ & $727 \cdot 85$ & $7 \cdot 27(h)$ \\
\hline — crystallized.. & $\overrightarrow{\mathrm{C}} A q^{2} \quad 9 \cdot 5$ & $\overline{\mathrm{C}} A q$ & $\left\{\begin{array}{c}\overrightarrow{\mathrm{C}} A q \text { 肯 } \\
8 \cdot 96\end{array}\right.$ \\
\hline Columbic........ & $\mathrm{Cb} \quad 19$ & $\ddot{\mathrm{C} b}=2607 \cdot 43$ & $19 \mathrm{Cb}(i)$ \\
\hline Ferroprussic ...... & ... & . & $7 \cdot 33(k)$ \\
\hline
\end{tabular}


and Notice of a new analytical Scale of Equivalents.

TABLE (concluded).

\begin{tabular}{|c|c|c|c|}
\hline & Thomson. & Berzelius. & Mean. \\
\hline Fluoboric ........ & $4 \cdot 25$ & $\cdots$ & $4.25 \mathrm{FIB} ?$ \\
\hline Fluoric ......... & Fn 1.25 & FIH $\quad 2 \cdot 4.3$ & $\left\{\begin{array}{l}1.3 \mathrm{Fn} \\
2.43 \mathrm{FIH}\end{array}\right.$ \\
\hline Formic......... & $4 \cdot 625$ & 463.93 & $4: 64(a)$ \\
\hline Gallic .......... & $7 \cdot 75$ & $791 \cdot 78$ & $7 \cdot 85$ \\
\hline Hydriodic... . . . . & HI $15 \cdot 625$ & $\cdots$ & 16. $\quad(g)$ \\
\hline Hydrobromic .... & $\ldots$ & $\ldots$ & $10 \quad(g)$ \\
\hline Hydrocyanic ..... & $\mathrm{C}^{2} \mathrm{NH} \mathrm{3.375}$ & $342 \cdot 39$ & $3 \cdot 4$ \\
\hline Iodic . . . . . . . . & $\because 20.5$ & $2078 \cdot 29$ & $20-8$ \\
\hline Lactic . . . . . . . . & $5 \cdot 75$ & $\ldots$ & $5 \cdot 78(a)$ \\
\hline Molybdic....... & M̈o $9 \cdot$ & 898.525 & $9 \cdot$ \\
\hline Molybdous ...... & М̈o 8 . & $\cdots$ & $8 \cdot$ \\
\hline Muriatic ....... & $\mathrm{ClH} 4.625$ & 45513 & $4 \cdot 58$ \\
\hline Nitric ......... & $\ddot{\mathrm{N}} 6.75$ & $677 \cdot 036$ & $6 \cdot 76$ \\
\hline Nitrous ......... & $\dddot{N} 5 \cdot 75$ & $\dddot{\mathrm{N}} 477.036$ & $\ddot{N} 5 \cdot 76(l)$ \\
\hline Oxalic ......... & $4 \cdot 5$ & $452 \cdot 875$ & $4: 51$ \\
\hline - crystallize $\mathrm{d}$ & $\ddot{C}^{4} A q^{4}{ }^{\prime}$ & $\ddot{C}^{2} A q^{9} 78 \cdot 9$ & $\ddot{C}^{2} A q^{9} 7 \cdot 88(m)$ \\
\hline Phosphoric ..... & 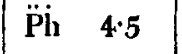 & $\mathrm{Ph}^{8} 892 \cdot 31$ & $\ddot{\mathrm{Ph}} \cdot 8 \cdot 92$ \\
\hline Selenious. . . . . . & $\ddot{\text { Se }} 7$ & $694 \cdot 582$ & $6 \cdot 97$ \\
\hline Selenic ... . . . . . & $\ldots$ & $\ddot{\text { Se }} 794: 582$ & $7 \cdot 97(n)$ \\
\hline Silica ......... & $\dot{\mathrm{Si}} \quad 2$ & $\dddot{\mathrm{Si}} \quad 577 \cdot 478$ & $\dot{\mathrm{Si}} \quad 2 \quad(0)$ \\
\hline Succinic ........ & $6 \cdot 25$ & $627 \cdot 85$ & $6 \cdot 27(a)$ \\
\hline Sulphurous ... . . . & $\ddot{\mathbf{S}} \quad 4 \cdot$ & $401 \cdot 165$ & $4 \cdot$ \\
\hline Sulphuric ...... & $\dddot{\mathrm{s}} 5$ & $501 \cdot 165$ & 5 \\
\hline Tartaric ........ & 8.25 & $834 \times 49$ & $8.27(p)$ \\
\hline —_ crystallized & $\overline{\mathrm{T}} A q^{\prime} \quad 9.375$ & $\ldots$ & $9 \cdot 4$ \\
\hline Titanic .......... & $\ddot{\mathbf{r}}$ & $589 \cdot 092$ & 5.95 \\
\hline Tungstic. & $\ddot{\Gamma} \dot{18} \quad 18.75$ & 1483.2 & $17 \cdot 9(q)$ \\
\hline
\end{tabular}


(a.) Acetic, Succinic, \&c.--The slight augmentation in the decimal is required for the increased estimate of the atom of carbon.

(b.) Antimonic.-Thomson's number is adopted for the simplicity of its relation to bases, in connection with the considerations in the note on antimony (ubi supra), but with the qualification there stated.

(c.) Arsenious, Arsenic.-It is difficult to read the account of Berzelius's investigations (Ann. Phil. xv: 352.) without feeling convinced by them. Those of Thomson (First Principles, i. 229) are almost equally convincing; yet both cannot be right. The sulphurets of arsenic appear, in Berzelius's paper, to consist respectively of $A s S^{2}$ and $A s S_{2}$, analogous to Thomson's constitution of the acids; which, having also the advantage of simplicity, in relation both to the bases with which they combine, and the oxygen they contain, seems rather entitled to preference.

(d.) Benzoic.-If carbon be $0 \cdot 76$, benzoic acid will be $15 \cdot 15$. But the mean between Thomson's and Berzelius's number for carbon is a fraction below 0.76 , whence the number adopted.

(e.) Boracic.-See the note on Boron.

(f.) Perchloric.-Berzelius's reasons for giving this acid a different constitution from that assigned by its discoverer (First Princ. i. 85) not appearing, the latter is adopted.

(g.) Chloriodic, \&c.-Calculated from the components in the former table.

(h.) Citric.-About the composition of crystallized citric acid there is some obscurity; which, though of little importance in chemistry, is otherwise in extemporaneous pharmacy, in which its neutralization is a frequent desideratum.

The most satisfactory analyses of it are those of Berzelius (Ann. Phil. v. 93.), and of Prout (Phil. Mag. and Annals, iii. 109), which nearly coincide: the former giving the crystals 17 per cent of water; the other resolving them into

Carbon........... 6 atoms.

Oxygen ......... 3 atoms.

Water............ 5 atoms.

Chemists are generally agreed in making the dry acid consist of 4 atoms of carbon, 4 atoms of oxygen, and 2 atoms of hydrogen: hence Dr. Prout's statement gives 2 atoms of water to $1 \frac{1}{2}$ acid; which is confirmed by Berzelius's tahle (Essai), as well as by the quantity of water above stated. But 3 atoms of acid to 4 of water is so strange a combination, as not easily to obtain our acquiescence. The equivalent weight would turn out Acid

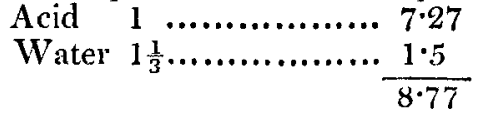

Thomson 
Thomson and Ure agree in assigning 2 atoms of water to 1 of acid; but the latter reduces the atomic weight to 8.375 (Dict., 2nd edit., Appendix, 84); the latter raises it to 9.5; pointing out however, in a note, its variance from his own analysis. (First Principles, i. 123, note.)

The apparent facility of determining the atomic weight of these crystals would lead us to impute the differences above quoted, to inconstancy in their water of crystallization. But having generally found this equivalent between 8.77 and 9', I suppose the ordinary constitution to be Acid 1 .. $7 \cdot 2 \cdot 27$ Water $1 \frac{1}{2} \ldots 1.6875$

And assume the equivalent $8 \cdot 96$.

(i.) Columbic.-See the note on Columbium.

$8 \cdot 9575$

(k.) Ferro-prussic.-Of the discordant data relating to the atomic weight of this acid, an experiment of Dr. Ure's (Dict., 2nd edit., Appendix, 805) seemed the most direct; but subject. to the uncertainty of all atomic deductions from precipitation with salts of lead, excess of which is apt to fall with the precipitate, as was observed some years since by Berzelius.

Some experiments of mine, guided by Mr. Porrett, give 13.28 for the atom of ferro-prussiate of potash ; constituted as follow :

$$
\begin{aligned}
& \text { Potassium...... 4.95 }=1 \text { atom. } \\
& \text { Oxygen....... 1.5 }=1 \frac{1}{2} \text { atom. } \\
& \text { Hydrogen..... 0.19 }=1 \frac{1}{2} \text { atom. } \\
& \text { Cyanogen.... 4.92 }=1 \frac{1}{2} \text { atom. } \\
& \text { Iron ............ } 1.72=\frac{1}{2} \text { atom. }
\end{aligned}
$$

If this be, as I believe, anhydrous ferro-prussiate of potash, the acid is 7.33: but it may be construed in other ways; and there is an anomaly about the half atoms, which becomes still more perplexing in prussian blue, composed of $1 \frac{1}{2}$ atom of acid to 1 atom of red oxide of iron, or rather of 3 atoms of acid to a double atom of oxide. I had therefore some hesitation in putting the dry acid on the scale, where it is accompanied with a? The composition of the crystallized acid I have not ascertained : that of the salts corresponds in analysis (though differing in theory) with the previous determinations of Berzelius.

(l.) Nitrous.-It is almost superfluous to remark, that the nitrous acid of Berzelius is the hyponitrous of English chemists.

(m.) Oxalic.-See the note on Benzoic Acid (d). The crystals found by Thomson to contain 4 atoms of water (First Princ.) having occurred to no one else, seem to be the result 
of some artifice in the manufactory, for commercial advantage, and are therefore neglected.

(n.) Selenic.-Discovered by Sertuerner, since the publication of 'Thomson's book.

(o.) Silica.--See note on Silicon.

(p.) Tartaric.-Berzelius's number contains 5 volumes, or $2 \frac{1}{2}$ atoms (according to our system) of hydrogen. The analyses of Thomson and Prout coincide in giving it 2 atoms, which is therefore regarded as its true composition. The augmentation in the third column is due to carbon.-See note $(b)$.

(q.) Tungstic. - See note on Tungsten.

Having now submitted to the correction of your readers the leading equivalents, leaving the bulk to be seen on the scale itself, I wish to add a short notice of what is distinctive in the construction of the instrument.

The object was, to contain in portable compass, of easy reference, and subject to the sliding scale, all the salts and precipitates used in practical chemistry, and their secondary and elementary components; multiples of the elementary atoms occurring in vegetable and animal analysis, and of water; and to present at one view a general table of atomic weights, simple and compound, referable by moving the slider, to either the hydrogen or oxygen scale.

The symbols of Berzelius offered the compactness and facility of arrangement, which were the first requisites, with the further advantage of exhibiting the atomic construction of every substance contained; a point of some importance, as will presently appear, in apportioning compound salts, and convenient in looking out the ingredients of complicated substances, as phosphoric and hydrocyanic acids. Their deficiency, for our present purpose, was in conspicuity, which I have endeavoured to supply as follows:

Where many of the symbols had the same initial, the English is substituted in some of them for the Latin one: as $\mathrm{T}$, tin; An, antimony; for Su, stannum; St, stibium; \&c. \&c. as explained in an index-table attached to the scale. Acids and negative bodies are distinguished by upright letters, the others being inclined; as $\dddot{\mathrm{S}}$ sulphuric acid, $\mathrm{Cl}$ chlorine, $\boldsymbol{P o}_{0}$ potash, $\boldsymbol{H}$ liydrogen; and Salts by combination of the upright

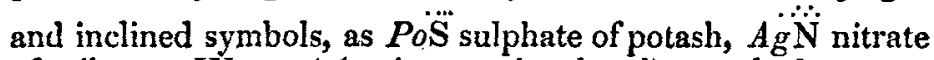
of silver. Water ( $A q$, in running hand) attached to any symbol, shows it to be a hydrate, and generally crystallized; 
So $A q^{10}$, sulphate of soda, crystallized, 10 atoms of water; T $A q^{\prime}$, tartaric acid, crystallized, 1 atom of water. The simple bodies are designated in that massive letter, called by printers "Egyptian."

Oxides being also distinguished by superimpressed dots, expressing the number of atoms of oxygen, thus leave the substances without a generic sign, so reduced in number, as to make the privation almost answer the purpose of one.

The following arrangement, added to these distinctions, render this scale (with a little practice, for chemists not familiarizer to the symbols) easier of reference than others much less comprehensive; so at least it is found in my own practice.

The scale is the same length as Wollaston's, but double, opening, bookwise, on hinges, and having of course two sliders, which are on the outsides. Within, is on one side a set of index-tables illustrative of the symbols; on the other, a letter-press explanation of the distinctive objects and use of the instrument.

The principal working scale is occupied entirely with the tests, salts and precipitates, arranged in four columns as follows; each column being headed with the generic symbols of its contents.

In the column left of the slider,--muriates, nitrates, borates, and $a$ few sulphites, arsenites and silicates.

In the outer column on the left, - sulphates, arseniates, phosphates, and a few tungstates.

In the first column on the right of the slider,-carbonates, acetates, and a few chromates and chlorates.

In the outer column on the right, - tartrates, oxalates, citrates, and a few ferro-prussiates and benzoates.

Triple, quadruple and compound salts, being heavy, fall near the bottom; and their long symbols crossing two columns, readily strike the eye.

The other scale contains the simple bodies, binary compounds, and multiples, having four columns on the right of the slider, and five. On the left, each column being headed with its contents.

On the right side are negative substances, chlorides, bromides and the multiples. On the left, neutral and positive substances, and iodides.

Simple bodies are on the columns next the slider (except a few displaced to prevent crowding); oxides in the two succeeding columus to the left; and sulphurets, phosphurets, \&c. in the two columus furthest left. 
Acids are on the column next the slider to the right; crystallized and hydrated acids in the succeeding column; and chlorides in the two columns furthest right. Multiples of oxygen, 1 to 12, are in the second column; of hydrogen, 10 to 50 , and carbon, 2 to 10 , in the third; and of nitrogen, 1 to 5 , and water, 1 to 25 , in the outer one.

Iodides and bromides, being heavy, are all near the font, on their respective sides; and therefore easily found, without crowding the other substances, by confining them to particulár columns.

In linking from column to column, where it could be done, to prevent the embarrassment of needless multiplication of lines, precision has been allowed to give way in a few unimportant cases; but the deviation bas rarely amounted to an hundredth part, particularly on the scale of salts.

The salts not packing so close as the binary compounds, and hence requiring a slider with longer degrees, an adjusting line $-\mathbb{T}$ is drawn across the face on each side, to set the two scales in accordance. Thus, when a salt and a chloride are to be used together; when the binary or elementary ingredients of a precipitate are to be ascertained; or, in short, whenever the relations between salts and binary compounds or simple bodies are to be examined,-each slider must be set with the same number against the line $\boldsymbol{b}-\mathbb{T}$, and they correspond throughout.

As a general table of equivalents, set 1.0 against $O$ (oxygen), and the numbers are on the oxygen scale; then move the slider and bring 8 against $O$, and the numbers are on the hydrogen scale, disregarding the decimal point. In the latter case the scale of salts must have its numbers corre-: spondingly decupled.

The advantage alluded to in the outset of this notice, as: belonging to the analytical character of these symbols, in cases of compound salts, may be thus illustrated. Suppose we have to prepare acetate of alumina from alum and acetate of lead: the symbol shows that alum contains four atoms of sulphuric acid; acetate of lead but one atom of oxide; and hence that four atoms of the latter salt are requisite for throwing down the acid; and that three atoms of acetate of ammonia will remain in the solution. So if we use cream of tartar, red sulphate of iron, dichloride of lime, \&c. we are guided at once by the symbol what proportions to employ, accordingly as the acid or base be the subject of operation. A similar convenience is afforded in looking out the quantitative ingredients of a compound salt.

These advantages are only in promptitude; for a knowledge 
of the atomic construction of each substance is necessarily presupposed: and hence this scale is addressed less to the manufacturer or learner, than to the practical chemist.

\section{I am, Gentlemen, yours, \&c.}

John Prideaux.

P.S.-In several scales that have fallen in my way, the stretching of the paper, in pasting, has produced important deviations from the original impression. A simple contrivance remedies this. A box tablet, the full length of the slider, and grooved to fit, is correspondingly graduated on each side of the groove. The slider is placed in this, to receive the graduated paper; which being pasted, is allowed to remain until sufficiently elongated by the humidity. It is then fixed; and such of the graduations as are out of place, by the irregular stretching of the paper, are rectified by pressure with the nail. 'The slider being now put in its own place, the side pieces, having been pasted at the same time, will be found nearly to correspond, and may be further stretched or shortened, and any irregularities adjusted, on comparison with an uncut impression, by the action of the nail, as before.

LXVI. Narrative of an Excursion to the Summit of the Peak of Teneriffe on the 23rd and 24th of February 1829 : with some Remarks on the Geology of that Island. By RoBERT Edward Alison, Esq.

\section{[Concluded from p. 251.] \\ On the Geology of Teneriffe.}

A $\mathrm{T}$ every step we take in Teneriffe, unequivocal marks ap$A$ pear of the great revolutions that have taken place upon its surface by volcanic action: such as craters of enormous extent and depth; conical mountains produced by eruptions; currents of lava which have flowed in every direction; beds of black and white rapilli, and tufa; with the sulphureous fumes from the Peak indicating an active state of combustion, which in a moment may be the cause of new disasters.

The lavas are of endless variety, and their appearance is variously modified, according to the heat and pressure they have been subjected to; and frequently there is a heaving-up of the strata from central points, from which they dip away in various directions as if they were elevated from the bottom of the sea by the pressure of elastic vapours, which have changed the lower strata of the island from their horizontal position to their present one of great inclination.
N.S. Vol. 8. No. 48. Dec. 1830.
$3 \mathrm{~K}$
The 